\title{
A Review Paper on the Emergence of Sixth Sense Technology and its Applications
}

\author{
Sabahat \\ Bachelor of Engineering \\ Dept. of Computer \\ Engineering YCET, Jammu, India
}

\author{
Indu Jamwal \\ Bachelor of Engineering \\ Dept. of Computer \\ EngineeringYCET, Jammu, India
}

\author{
Akanksha Bali \\ Assistant Professor \\ Dept. of Computer \\ Engineering \\ YCET, Jammu, India
}

\begin{abstract}
There are five basic senses in living beings - hearing, seeing, smelling, tasting and feeling. These senses are evolved through millions of years. Now we are moving into the era of $6^{\text {th }}$ sense technology. Basically it sound supernatural, which is beyond science. Sixth Sense Technology is a neck worm wearable gestural interface that amplifies the physical world around us with the digital information. Technology that plays with the human gestures to make the world more interactive and work flow much easier. Its basic use is to cause computers to adapt to human needs. It's a developing technology, once fully developed it has the potential to give human being any source of information about the world around him. The aim of sixth sense is to let the computer assist human in making correct decisions by molding information into various forms. Sixth Sense technology bridges the gap between tangible and non-tangible world. $6^{\text {th }}$ sense is like breathing a new life in the world of virtual reality. Using the $6^{\text {th }}$ sense technology, we can easily change or develop the developing cities or countries into smart cities and developed countries.
\end{abstract}

\section{Keywords}

Camera, projecter, mirror, microphone, color markers, gestures.

\section{INTRODUCTION}

In the rising world of technology, we follow different technologies for specific tasks in our daily life. Moreover, technology has been running in our daily lives in all sectors, no matter what industry you are dealing with, it has an impact in an unquestionable manner. Today each and every member, regardless of age is aware of the technical devices. All over we can say is "Technology is our useful servant". However, technology is emerging rapidly and there are no chances for being slowing in nearer future. Since for last many years, technology has taken the world in terms of the products we purchase, communicate, the way we live, learn and has brought lots of changes with this constant advancement of technology. The technology which we use is constantly evolving due to which innovations takes place very frequently in today's world. Thus the size of computer devices are getting smaller day by day. One such innovation is Sixth Sense Technology. Sixth Sense is a gesture based wearable devise developed at MIT Media Lab by Steve Mann in 1994 and 1998, and further developed by Pranav Mistry in 2009. It comprises a headworm or neckworm that contains both a data projector and camera.Headwom versions are built at Media mit Lab in 1997 that combined cameras and illumination systems for interactive photographic art, and also included gesture recognition (e.g finger tracking using colored tapes on the fingers).[1]

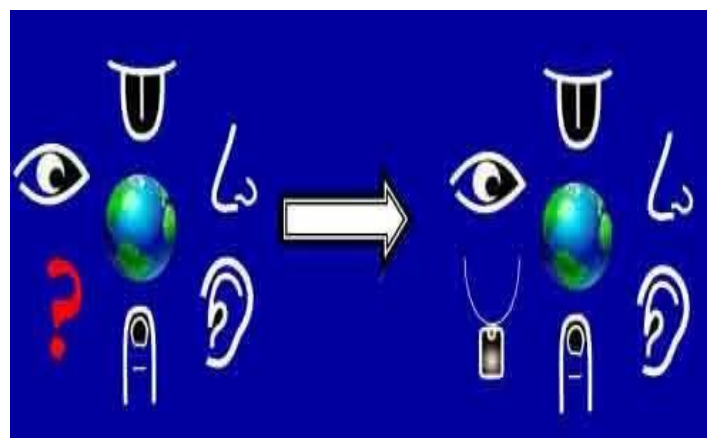

Figure1: Existence of Sixth Sense Technology

\subsection{Why Sixth Sense Technology?}

Sixth sense technology is a elevated platform which connects the physical world with the digital information using natural hand gestures to interact with that information in a simplest way. This technology has a wide application in the field of artificial intelligence.

Sixth sense technology has a power of connecting the real world with the digital world, and displaying the information on the web. It recognizes the objects around you, displaying information automatically and letting you access it in any way you want, and you can carry it to anywhere. The sixth sense technology sample model shows various applications that displays the ability, usefulness, viability and flexibility of the system. [2]

\section{$1.26^{\mathrm{TH}}$ SENSE TECHNOLOGY PROTOTYPE}

Sixth sense is a mini projector coupled woth a camera and a smartphone, designed for obeying hand gestures. Sixth sense is a extra sensory perception that aims at a more developed future with both physical and digital world connected without the help of hardware devices.

However, instead of requiring you to be in front of a big screen like computer, laptop or mobile phone, Sixth Sense can do its magic everywhere. [3]

The basic components of 6th sense device are;-

- Camera.

- Projector.

- Colored markers.

- Mirror

- Smart phone. 


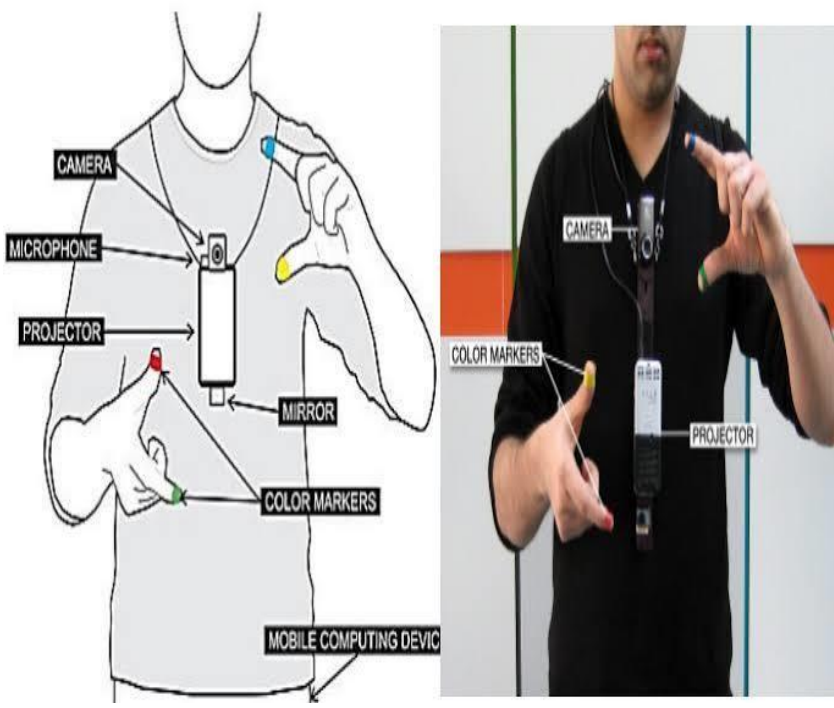

Figure2: Components of Sixth Sense Technology

\subsubsection{Camera}

The function of the camera is like that of a human eye, the only difference being it will provide digital information. Camera recognizes and tracks user's hand gestures and physical objects around us to be used as interfaces.

\subsubsection{Projector}

The projector is basically an output device which projects visual information enabling Surfaces, walls and physical objects to be used as interface. The projector itself contains a battery inside, with a life span of 3 hours.

\subsubsection{Colored Markers}

Colored markers are placed at the tip of the user's fingers using simple computer vision techniques. It helps the webcam to track the movement of the fingers. Marking the user's fingers with red, yellow, Green and blue tape helps webcam recognize gestures. The movements are arrangements of these fudicials are interpreted into gestures that act as interaction instructions for the projected application interface.

\subsubsection{Mirror}

Mirror is placed just below the projector. The projector can project the information in any direction with the help of a mirror which can be tilted in any direction as per the user's requirement.

\subsubsection{Mobile Device}

Mobile device may be a laptop, PDA, smart phone etc. these are connected to other hardware devices and send information to the projector for projection. The important thing is that the device is a mobile device. It means it is so light that we can take it with us where we want to. It is as small a cell phone and is so simple to use. [8]

\section{WORKING of SIXTH SENSE TECHNOLOGY}

Sixth sense device examine what a person view and improves the surfaces and physical object where individual is interacting with. To form a Brand new interaction experience, a number of gadgets like projector, mobile phone and a webcam have been combined which is done by the researchers. The various object around us, Presenting information and provide access in any way what user wants in a simple way is identified by sixth sense technology. The technology is mainly based on hand gesture recognition, image capturing, processing and manipulation etc.
The Working Of The Sixth Sense Device

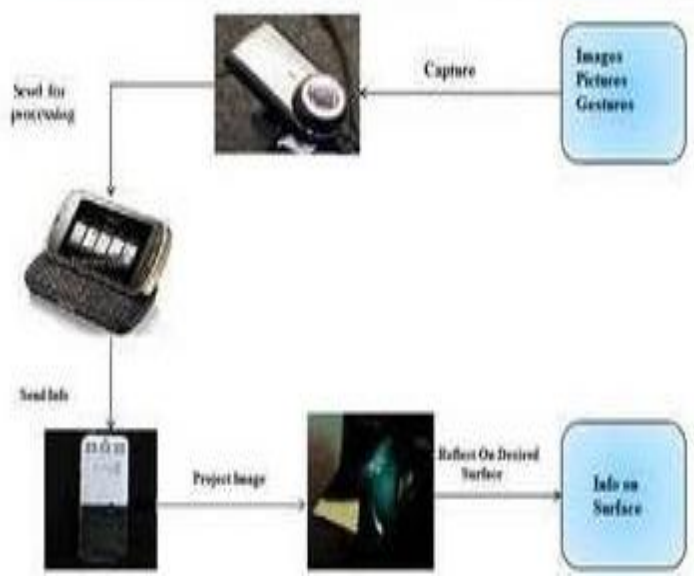

Figure 3: Working of Sixth Sense Technology [8]

The camera is used to capture and recognize hand gestures of the user, individuals, images and physical objects using computer vision based technologies, while the projector is used to project visual information on walls or on any physical object around us to be used as an interface. Other hardware includes mirror and colored caps to be used for fingers. The Sixth Sense Technology has a camera uses the video stream tracks the location if the tips of the fingers is used to identify the gestures. The process is done using some techniques of computer vision. Basically it is device which is a mini projector and which can be projected on any surface. It carries the information stored in it and also collects information from the web. It is the one which obeys hand gestures of ours and give us what we want to see and know. it is the combined technology of computer along with the cell phone. It works when a person hang it on his neck and start projecting through the micro projector attached to it. Our fingers work like a keyboard as well as the mouse.

\section{APPLICATIONS \\ 3.1 Motion Capture}

The new camera was praised by majority people at the time of demonstration. The pictures can be edited, managed into galleries and shared on any interface. The data is stored inside an inbuilt storage device. At the time of using a surface, the entire data is taken into that surface and after editing, it is stored in the device.

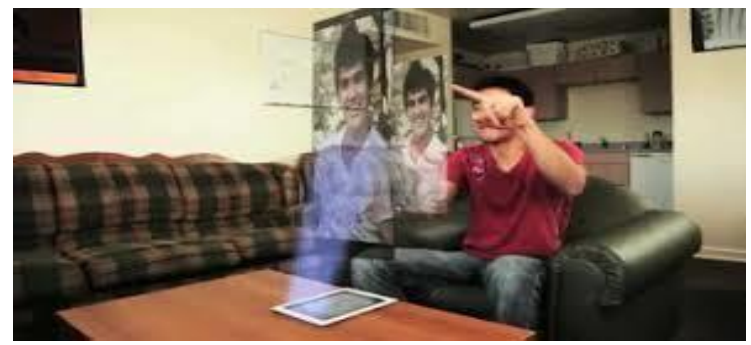

Figure 4: Motion capture

\subsection{Capturing Photos using Fingers}

The burden of carrying a camera and keeping it safe and sound on a trip can now be avoided by simply using the Sixth sense technology. The sixth sense computer functions as a camera. If you make the square using your index fingers and thumb then your picture is clicked by the camera. 


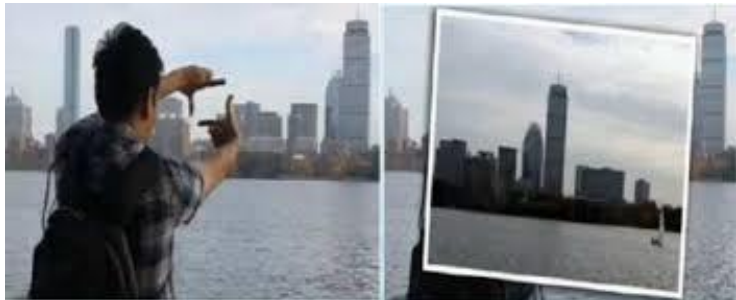

Figure 5: Capturing image using fingers

\subsection{Check the Brand of the Product}

A product of the best brand can be chosen.

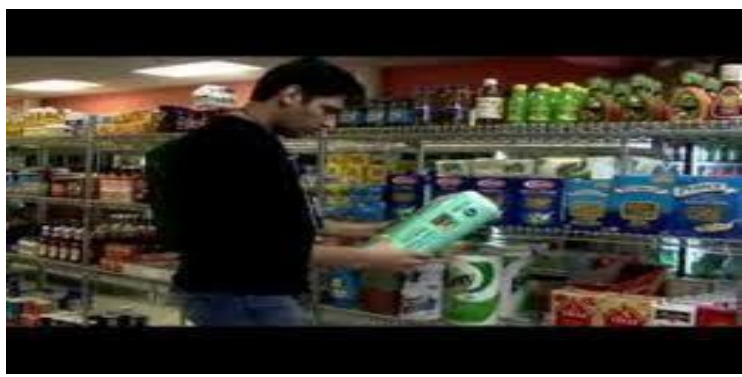

Figure 6: Check the brand of the product.

\subsection{Reviewing Flight Status}

Any background can be used to project a screen, on which the status of flight can be checked by placing the ticket in front of this technology.

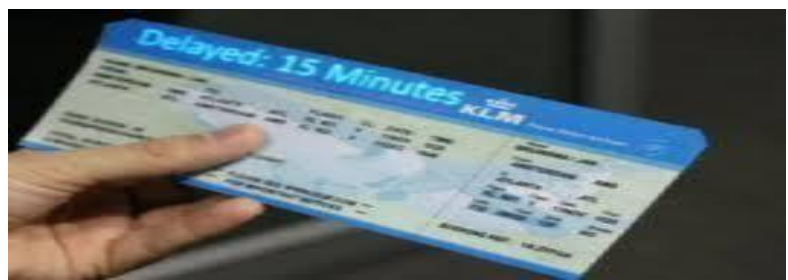

Figure 7: Reviewing Flight Status

\subsection{Time without watch}

Time can be viewed merely by drawing a circle on the wrist instead of physically wearing a wristwatch.

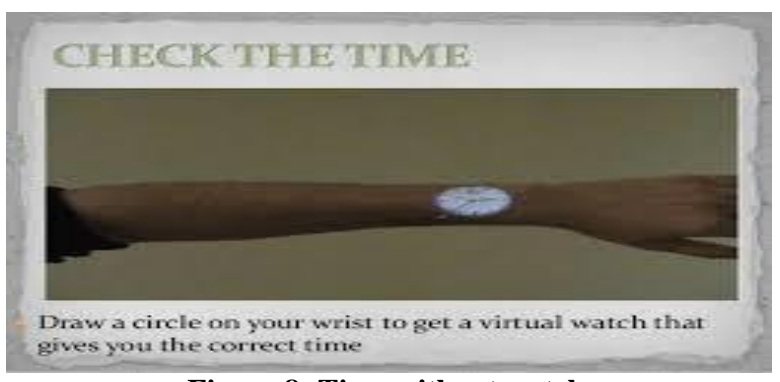

Figure 8: Time without watch

\subsection{D Drawing}

Provides a pencil that allows users to draw in $3 \mathrm{D}$, a good way to learn for the beginners in the field of 3D modeling.

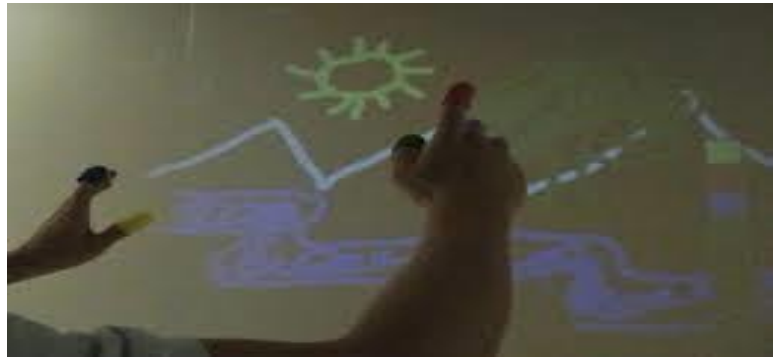

Figure 9: 3d drawing

\subsection{Call using palm as dialer}

It gives the provision of using the hand as a screen onto which the dialer is projected, using which an individual can make a call.

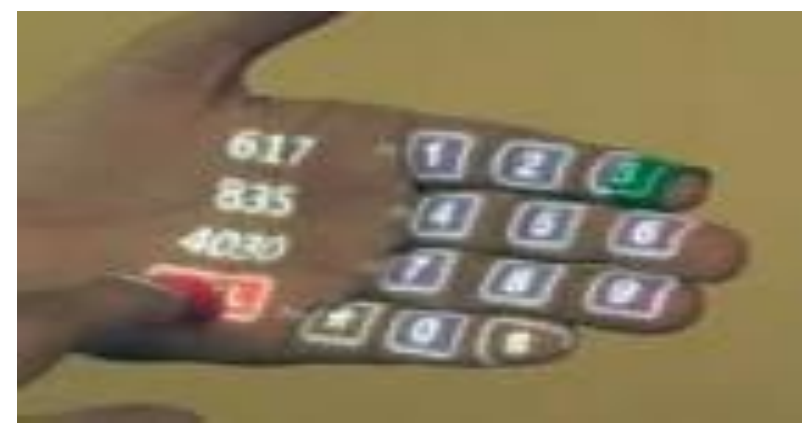

Figure 10: Call using palm as dialer

\subsection{Video newspaper}

It determines the news headline and the displays the appropriate video.

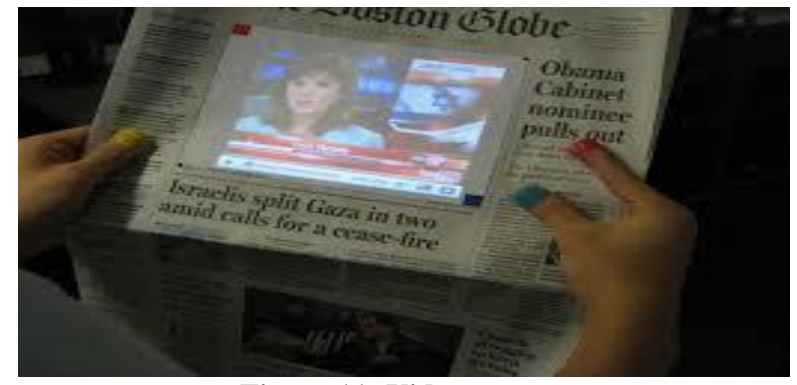

Figure 11: Video newspaper

\subsection{Zoom in Zoom out}

It helps to view images and related things in the way one wants to see. [6]

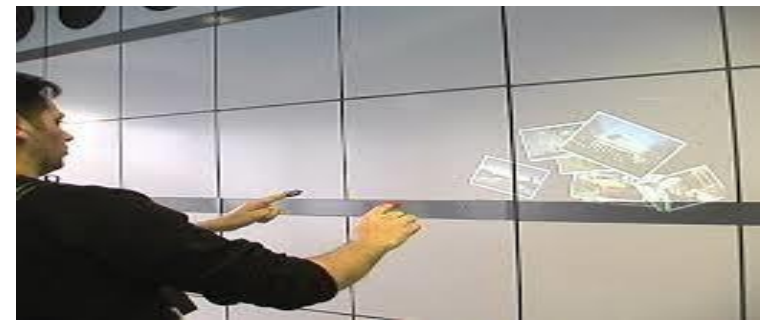

Figure 12: Zoom in Zoom out 


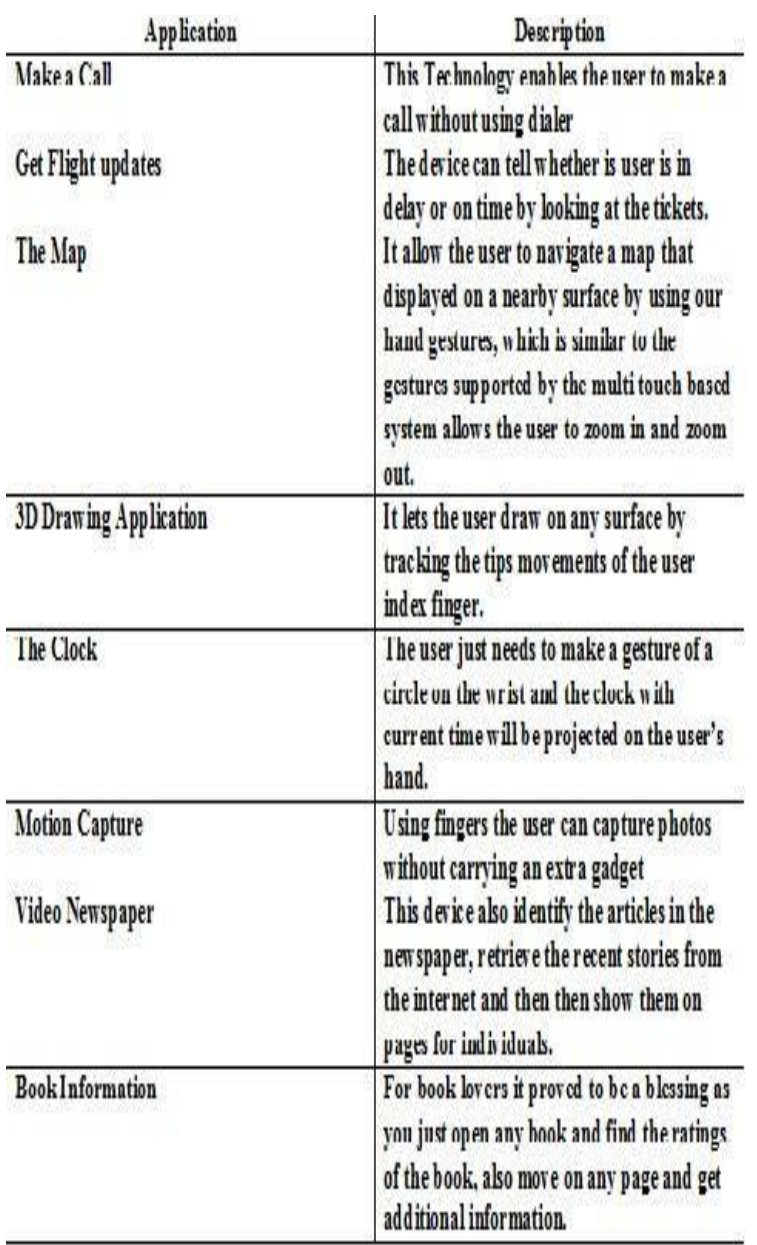

Figure13: Applications of Sixth Sense Technology [7]

\section{ADVANTAGES OF SIXTH SENSE TECHNOLOGY}

a) The digital information and its objects are combined into the physical world by using the Sixth sense interface, thereby making the entire world as our own computer.

b) Sixth Sense makes machines like computers to adapt to human needs and not the other way round.

c) Hand gestures are used to communicate with digital information, multi-touch and multi-user interaction is also supported.

d) Data from machine is directly accessed into real time. It is open source and it is cost effective and map idea can be minded anywhere.

e) Our relevant information is provided by the gesturecontrolled wearable computing device that manipulates any surface into a display.

f) It is portable

g) Comparatively easy to carry as can be worn in our neck

h) Even a naïve man with little or no knowledge of mouse and computer can use this device.

i) The cost that arose for the making of the sixth sense technology proto type is very low. A normal sixth sense device sums up to $\$ 300$. [5]

\section{DISADVANTAGES OF SIXTH SENSE TECHNOLOGY}

a) Excessive use of a technology can cause addiction and can hamper social life as well. It will in-turn diminish humanness.

b) Exposure of rays on surfaces like human arms can lead to health problems.

c) This technology will affect the hardware market and will result in less revenue being generated and lower the cash inflow.

d) It can affect the vision of the user because of its peculiar and better use at night time and in dark areas as compared to mornings and bright places.[5]

\section{CONCLUSION}

The Sixth sense technology is evolved to combine information into real world. The coming life is based on sixth sense. It can grant an simple power over equipments and machineries in industry. It can assist in enrooting multiple application areas for different engineers and builders upon their innovation, imagination, what's their requirement and how they need. Due to its worldwide application it is also Known as open source software. It is a replacement of Fifth sense Technology. The Sixth sense technology will bring a severe alteration in the area of science and technology.

\section{FUTURE SCOPE}

Further development in this technology will lead to evolvement of new markets. Hardware used in the current technology can be perfected as it plays an important role in this technology by interacting with the user. Security of the current technology can further be improved and more accuracy should be aimed for. Enhancements should be made so that visually impaired people can use this technology. The current technology is a little bulky to carry around, so few improvements can make it user friendly.

\section{REFERENCES}

[1] Sixth Sense 2009_http://en.wikipedia.org/wiki/SixthSense>

[2] M. Arora, "Basic Principles of Sixth Sense Technology", VSRD-IJCSIT, Vol.2(8), 687-693.

[3] B. Raksha , "Sixth Sense Technology OR WUW (Wear Ur World)", Research Expo International Multidisciplinary Research Journal Volume - II , Issue - II June - 2012

[4] M. Gupta, S. Sharma, "Virtual Class room using six sense Technology", IOSR Journal of Computer Engineering (IOSRJCE) Volume 6, Issue 4 (Sep. - Oct. 2012)

[5] N.Anand,N.Gaur,K.Choudhary"Sixth Sense In A State Of Radical Emergence"Volume 3,pp.527-532.

[6] J.Mehta,N.Nayani,L.Kurup,"A Review Paper On Sixth Sense Technology" Vol ume 4,pp. 3210-3213

[7] A. Chpra, A. Narang," A Study on the sixth Sense Tecnology and its various Threats", ISSN 0947-2239, vol. 4, pp. 663-670, 2014.

[8] Y. Jain, K. Ali," A Review Paper on Sixth Sense Technology and its Applications", ISSN-2349-6010, pp. 36-39, 2016. 